\title{
Improvement of Drug-Induced Cardiac Failure by NKH477, a Novel Forskolin Derivative, in the Dog Heart-Lung Preparation
}

\author{
Akira Fujita, Takashi Takahira, Makoto Hosono* and Keita Nakamura \\ Research Laboratories, Pharmaceuticals Group, Nippon Kayaku Co., Ltd., \\ 31-12, Shimo 3-chome, Kita-ku, Tokyo 115, Japan
}

Received October 17,1991 Accepted December 24, 199I

\begin{abstract}
The efficacy of NKH477, a novel water-soluble forskolin derivative, in improving cardiac failure was assessed in dog heart-lung preparations. Cardiac functions depressed by pentobarbital, propranolol or verapamil so that cardiac output had been reduced by about $40-50 \%$ of the respective control were all improved by NKH477 $(10-100 \mu \mathrm{g})$ in a dose-dependent manner. With $100 \mu \mathrm{g}$ NKH477, almost complete restoration of cardiac performance was attained in the respective cardiac failures. In the combination of NKH477 with ouabain $(30 \mu \mathrm{g}), 30 \mu \mathrm{g}$ of NKH477 completely restored the cardiac function depressed by pentobarbital, associated with a slight but not significant increase in heart rate. No arrhythmias were induced by any of the NKH477 doses used in the experiments. These results suggest that NKH477 should be subjected to clinical trials in the treatment of cardiac failure.
\end{abstract}

Cardiac glycosides have been widely used for the treatment of congestive heart failure. However, their narrow margin of safety and propensity to produce fatal arrhythmias have imposed serious problems on use. Recently, many novel nonglycoside cardiotonic drugs which include orally active $\beta$-adrenoceptor agonists and phosphodiesterase inhibitors have been developed (1). Most of these drugs produce their positive inotropic action by increasing intracellular cyclic AMP in the myocardium. Forskolin (Fig. 1), a diterpene obtained from Coleus forskohlii, also increases the intracellular cyclic AMP level in the myocardium and exhibits a positive inotropic effect (2). However, forskolin has not been available as a drug since it has poor water-solubility and low oral activity, although the unique ability

\footnotetext{
* To whom correspondence should be addressed.
}

of forskolin has been demonstrated to stimulate adenylate cyclase directly, not through a $\beta$-adrenoceptor-mediated mechanism $(3,4)$.

NKH477, 6-(3-dimethylaminopropionyl)forskolin hydrochloride (Fig. 1), is a novel watersoluble forskolin derivative (5). The cardiovascular profile of NKH477 was briefly reported previously (6). NKH477, like forskolin, stimulated adenylate cyclase directly and produced positive inotropic and vasodilator effects (6). The present experiments were designed to obtain information about the effects of NKH477 on the failing heart. We used the dog heart-lung preparation in which cardiac failure was produced by pentobarbital, propranolol or verapamil.

\section{MATERIALS AND METHODS}

The heart-lung preparation employed in this 


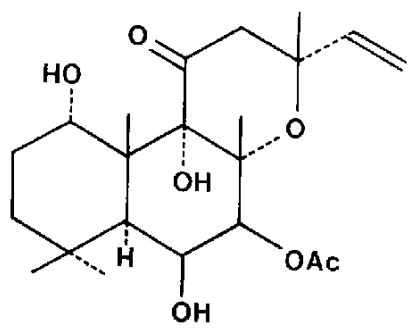

Forskolin

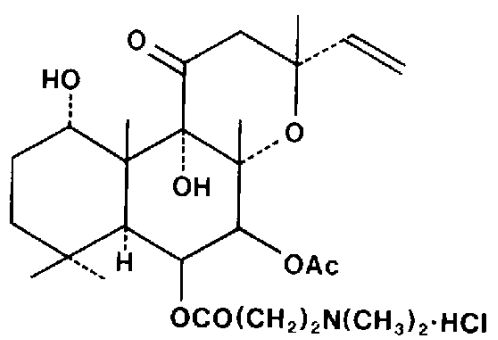

NKH477

Fig. 1. Chemical structures of forskolin and NKH477.

study was the same as described elsewhere in detail (7). Twenty-four heart-lung preparations were prepared from mongrel dogs of either sex, weighing $10-15 \mathrm{~kg}$ and anesthetized with sodium pentobarbital $(30 \mathrm{mg} / \mathrm{kg}$, i.v. $)$. A blood reservoir was primed with $500 \mathrm{ml}$ blood obtained from other mongrel dogs anesthetized with sodium pentobarbital $(30 \mathrm{mg} / \mathrm{kg}$, i.v.) and given calcium heparin $(500 \mathrm{U} / \mathrm{kg}$, i.v.). The level of blood in the reservoir was maintained at $5 \mathrm{~cm}$ above the level of the tricuspid valve. Aortic pressure, which was provided by a Starling pneumatic resistor, was maintained at $80 \mathrm{~mm} \mathrm{Hg}$. Cardiac output (not including coronary blood flow) was measured with an electromagnetic flowmeter (Nihon Kohden, MF-27), the flow probe (Nihon Kohden, FF-100T) of which was interposed between the brachiocephalic cannula and the Starling resistor. Left and right atrial pressures were measured with pressure transducers (Century Technology Co., CP-01). Left ventricular pressure was measured-with a pressure transducer connected to a cannula introduced into the left ventricle through the left subclavian artery. The maximum rate of rise in left ventricular pressure ( $\left.\mathrm{LV} \mathrm{dP} / \mathrm{dt}_{\max }\right)$ was obtained with an electronic differentiator (Nihon Kohden, EQ-601G). Heart rate was measured with a cardiotachometer (Nihon Kohden, AT-600G) triggered by left ventricular pressure pulses. All the cardiac variables described above were recorded on an ink-writ- ing recorder (Nihon Kohden, WI-681G). To determine cardiac function curves that relate cardiac output to left atrial pressure, the level of blood in the reservoir was elevated stepwise by $5 \mathrm{~cm}$ for $30 \mathrm{sec}$ up to $10 \mathrm{~cm}$ above the initial level. Such a procedure is designated as a competence test. To produce cardiac failure, sodium pentobarbital, propranolol or verapamil was cumulatively administered into the blood reservoir, until cardiac output was decreased by about $40-50 \%$ of the control value. Competence tests were also performed in each failing heart. NKH477 $(10-100 \mu \mathrm{g})$ was administered into the blood reservoir in a cumulative manner, and a competence test was carried out after each dose of NKH477. In the experiment of pentobarbital-induced heart failure, effects of the combination of NKH477 with ouabain were also examined. In that case, ouabain $(30 \mu \mathrm{g})$ was administered first and then NKH477 $(30-100 \mu \mathrm{g})$ administered later.

The drugs used were sodium pentobarbital (Tokyo Kasei), propranolol (Sigma), verapamil (Sigma), ouabain (Aldrich) and NKH477, 6-(3-dimethylaminopropionyl)forskolin hydrochloride (Nippon Kayaku).

The results were expressed as the mean value \pm S.E.M., unless otherwise noted. Statistical analysis was performed by analysis of variance and significant differences $(\mathbf{P}<0.05)$ were judged using Dunnett's test. 


\section{RESULTS}

\section{Pentobarbital-induced heart failure.}

Cardiac function curves obtained from all six experiments are presented in Fig. 2. Before the administration of sodium pentobarbital, the left atrial pressure and cardiac output were $4.7 \pm 0.5 \mathrm{mmHg}$ and $571 \pm 55 \mathrm{ml} / \mathrm{min}$, respectively, under baseline conditions $(\mathrm{n}=$ 6). On elevation of the level of blood in the reservoir to $10 \mathrm{~cm}$ above the baseline, left atrial pressure and cardiac output rose to $7.6 \pm$ $0.9 \mathrm{~mm} \mathrm{Hg}$ and $1077 \pm 59 \mathrm{ml} / \mathrm{min}$, respectively. After the administration of sodium pentobarbital (129 $\pm 37 \mathrm{mg}$, mean value \pm S.D.), the left atrial pressure and cardiac output were $8.0 \pm 0.9 \mathrm{mmHg}$ and $379 \pm 36 \mathrm{ml} / \mathrm{min}$ under baseline conditions and $15.6 \pm 2.0 \mathrm{mmHg}$ and $723 \pm 35 \mathrm{ml} / \mathrm{min}$ when the level of blood in the reservoir was elevated by $10 \mathrm{~cm}$, respectively. Consequently, the cardiac function curve was shifted downwards and to the right. Following the addition of NKH477 (10-100 $\mu \mathrm{g}$ ), the cardiac function curve depressed by pentobarbital was shifted upwards and to the left in a dose-dependent manner. With $100 \mu \mathrm{g}$ NKH477, almost complete improvement of the depressed cardiac function curve was

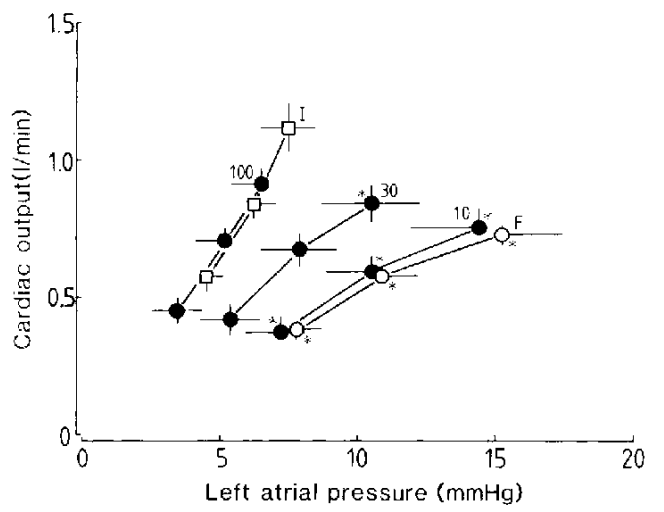

Fig. 2. Cardiac function curves in pentobarbital-induced heart failure (cardiac output vs. left atrial pressure). Each point represents the mean \pm S.E.M. of 6 preparations. $]$ Initial value, $\bigcirc$ Cardiac failure, $\mathrm{NKH} 477(\mu \mathrm{g}) .{ }^{*} \mathrm{P}<0.05$ vs. initial value. accomplished.

Under baseline conditions, the right atrial pressure rose from $1.8 \pm 0.4 \mathrm{cmH}_{2} \mathrm{O}$ in the control to $3.8 \pm 0.4 \mathrm{cmH}_{2} \mathrm{O}$ in cardiac failure preparations. The elevated right atrial pressure was lowered with NKH477 $(10-100 \mu \mathrm{g})$ in a dose-dependent manner and completely improved with $100 \mu \mathrm{g} \mathrm{NKH477,} \mathrm{as} \mathrm{shown} \mathrm{in}$ Fig. 3A.

The heart rate was $148 \pm 6 \mathrm{bcats} / \mathrm{min}$ in the control and decreased to $132 \pm 10$ beats $/ \mathrm{min}$ in the failing heart. The heart rate was in-
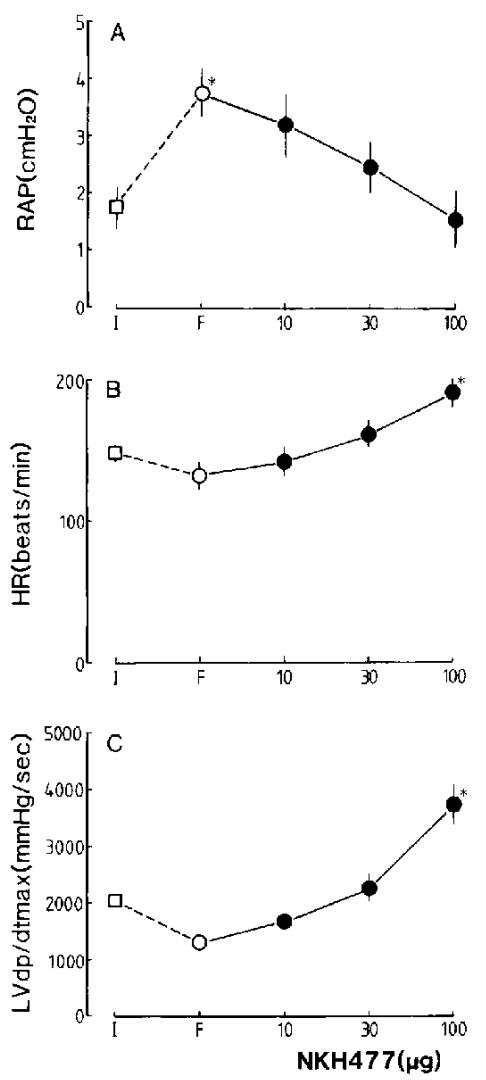

Fig. 3. Effects of $\mathrm{NKH} 477$ on right atrial pressure (RAP, A), heart ratc (HR, B) and the maximum rate of rise in left ventricular pressure $\left(\mathrm{LV} \mathrm{dP} / \mathrm{dt}_{\max }, \mathrm{C}\right)$ in the pentobarbital-induced heart failure. Values obtained just before the competence test at each dose of NKH477 are plotted. Each point represents the mean \pm S.E.M. of 6 preparations. I: Initial value, F: Heart failure. ${ }^{*} \mathrm{P}<0.05$ vs. initial value. 
creased with increasing doses of $\mathrm{NKH} 477$ and with $100 \mu \mathrm{g}$, the increase was about $28 \%$ of the control value (Fig. 3B).

The decrease in $\mathrm{LV} \mathrm{dP} / \mathrm{dt}_{\max }$ in the failing heart and its improvement with $\mathrm{NKH} 477$ are presented in Fig. $3 \mathrm{C}$. $\mathrm{LV} \mathrm{dP} / \mathrm{dt}_{\max }$ decreased in the failing heart was increased with increasing doses of NKH477; and with $100 \mu \mathrm{g}$, LV $\mathrm{dP} / \mathrm{dt}_{\max }$ was increased beyond the control value.

No arrhythmias were induced by NKH477 in any doses used.

\section{The combination of NKH477 with ouabain}

Effects of the combination of NKH477 with ouabain $(30 \mu \mathrm{g})$ were also examined on the pentobarbital-induced heart failure. The dcpressed cardiac function curve in the failing heart was partially improved with $30 \mu \mathrm{g}$ ouabain. Following the addition of NKH477 (30$100 \mu \mathrm{g}$ ), the cardiac function curve was further improved in a dose-dependent manner and almost complete improvement was accomplished with $30 \mu \mathrm{g}$ NKH477. The cardiac function curve was improved beyond the control value

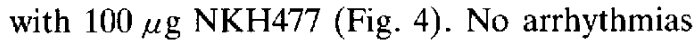
were induced by NKH477, even at $100 \mu \mathrm{g}$.

The elevated right atrial pressure and the decreased $\mathrm{LV} \mathrm{dP} / \mathrm{dt}_{\max }$ in the failing heart were also partially improved with $30 \mu \mathrm{g}$ ouabain and further improved with NKH477 (30$100 \mu \mathrm{g})$ in a dose-dependent manner. Right atrial pressure was completely restored with 30 $\mu \mathrm{g}$ NKH477. The heart rate, which had been decreased with sodium pentobarbital, was not changed with $30 \mu \mathrm{g}$ ouabain, but increased with NKH477 in a dose-dependent manner. However, with $30 \mu \mathrm{g} \mathrm{NKH} 477$, at which the cardiac function curve returned to the control value, the increase in heart rate was only about $12 \%$ of the control value and not significant (Table 1).

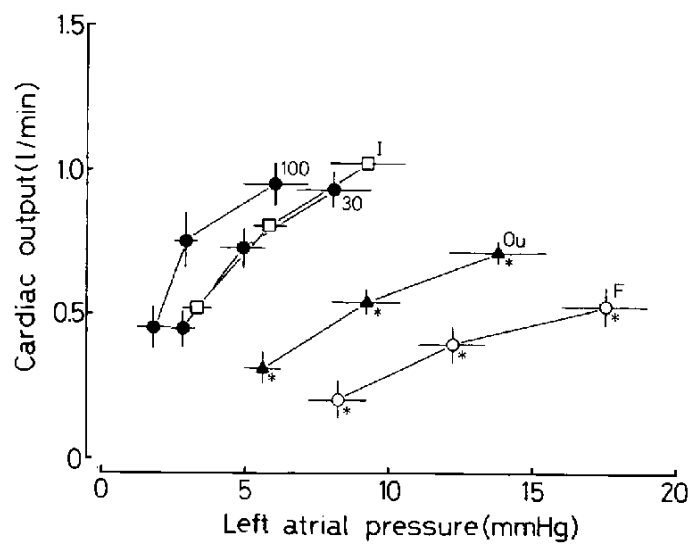

Fig. 4. Cardiac function curves determined with ouabain and NKH477 in pentobarbital-induced heart failure (cardiac output vs. left atrial pressure). Each point represents the mean \pm S.E.M. of 6 preparations. $\square$ Initial value, $\bigcirc$ Cardiac failure, $\Delta$ Ouabain $(30 \mu \mathrm{g})$, Ouabain $(30 \mu \mathrm{g})+\mathrm{NKH} 477(\mu \mathrm{g}) .{ }^{*} \mathrm{P}<0.05$ vs. initial value.

Table 1. The combined effects of NKH477 with ouabain on heart rate (HR), the maximum rate of rise in left ventricular pressure ( $\mathrm{LV} \mathrm{dP/dt}$ max $)$ and right atrial pressure (RAP) in the pentobarbitalinduced heart failure

\begin{tabular}{|c|c|c|c|c|c|}
\hline & Initial value & Heart failure & $\begin{array}{l}\text { Ouabain } \\
(30 \mu \mathrm{g})\end{array}$ & $\begin{array}{c}\text { Ouabain + NKH477 } \\
(30 \mu \mathrm{g}) \quad(30 \mu \mathrm{g})\end{array}$ & $\begin{array}{c}\text { Ouabain }+ \text { NKH477 } \\
(30 \mu \mathrm{g}) \quad(100 \mu \mathrm{g})\end{array}$ \\
\hline $\begin{array}{c}\mathrm{HR} \\
\text { (beats/min) }\end{array}$ & $123 \pm 9$ & $112 \pm 9$ & $110 \pm 4$ & $138 \pm 3$ & $169 \pm 4^{*}$ \\
\hline $\begin{array}{l}\mathrm{LV} \mathrm{dP} / \mathrm{dt}_{\max } \\
(\mathrm{mmHg} / \mathrm{sec})\end{array}$ & $1250 \pm 154$ & $900 \pm 73$ & $1133 \pm 131$ & $1683 \pm 224$ & $2283 \pm 467^{*}$ \\
\hline $\begin{array}{c}\mathrm{RAP} \\
\left(\mathrm{cmH}_{2} \mathrm{O}\right)\end{array}$ & $0.9 \pm 0.2$ & $3.1 \pm 0.3^{*}$ & $2.1 \pm 0.3^{*}$ & $1.0 \pm 0.2$ & $0.6 \pm 0.2$ \\
\hline
\end{tabular}

Values obtained just before the competence tcst at each administration of drugs are shown. Each value represents the mean \pm S.E.M. of 6 preparations. ${ }^{*} \mathrm{P}<0.05$ vs. initial value. 
Propranolol- or verapamil-induced heart failure Cardiac function curves obtained from each of the six experiments in propranolol- or verapamil-induced heart failure are presented in Figs. 5 and 6, respectively. After the administration of propranolol (22 $\pm 2 \mathrm{mg}$, mean value \pm S.D. $)$ or verapamil $(0.66 \pm 0.20 \mathrm{mg}$,

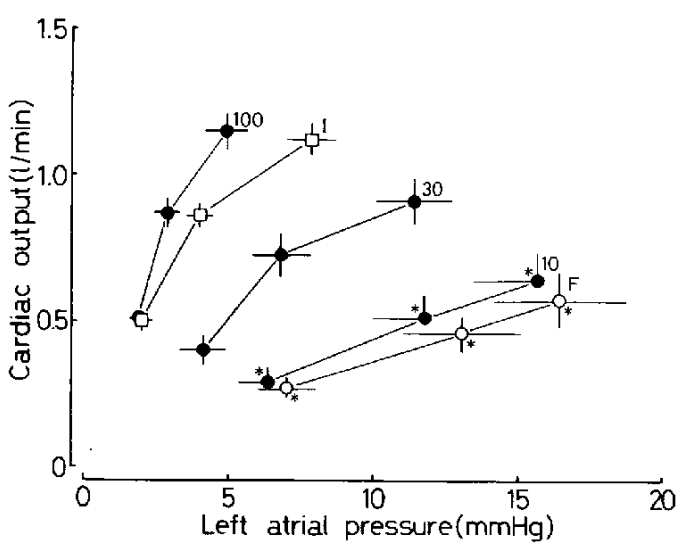

Fig. 5. Cardiac function curves in propranolol-induced heart failure (cardiac output vs. left atrial pressure). Each point represents the mean \pm S.E.M. of 6 preparations. $\square$ Initial value, $\bigcirc$ Cardiac failure, NKH477 $(\mu \mathrm{g}) .{ }^{*} \mathrm{P}<0.05$ vs. initial value.

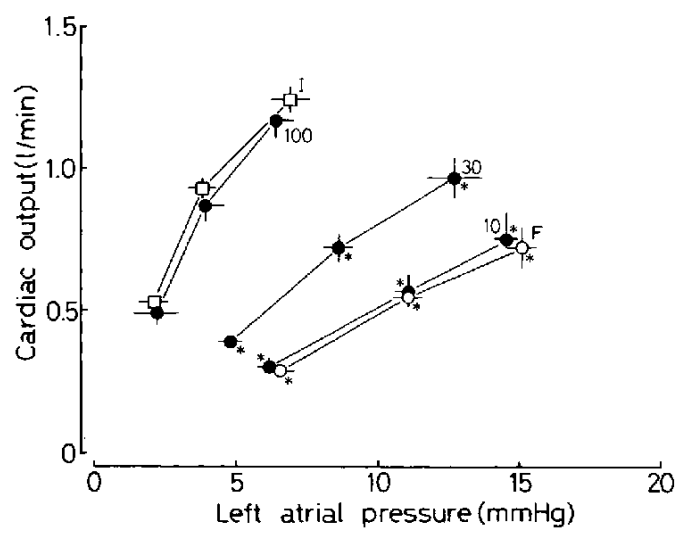

Fig. 6. Cardiac function curves in verapamil-induced heart failure (cardiac output vs. left atrial pressure). Each point represents the mean \pm S.E.M. of 6 preparations. $\square$ Initial value, $\bigcirc$ Cardiac failure, $\bigcirc \mathrm{NKH477}$ $(\mu \mathrm{g}) .{ }^{*} \mathrm{P}<0.05$ vs. initial value. mean value \pm S.D.), the cardiac function curve was shifted downwards and to the right as was the case with pentobarbital-induced heart failure. Following the addition of NKH477 $(10-100 \mu \mathrm{g})$, each depressed cardiac function curve was shifted upwards and to the left in a dose-dependent manner. In each heart failure, with $100 \mu \mathrm{g}$ NKH477, almost complete improvement of depressed cardiac function was accomplished, judging from the cardiac function curves. In propranolol- or verapamil-induced heart failure, changes in other cardiac variables (right atrial pressure, $\mathrm{LV} \mathrm{dP} / \mathrm{dt}_{\max }$ and heart rate) were also similar to those in pentobarbital-induced heart failure. Following the addition of NKH477, these changes were all restored in a dose-dependent manner (Table 2). No arrhythmias were induced by NKH477 at any of the doses used in each heart failure.

\section{DISCUSSION}

From the results presented here, it is clear that NKH477 can improve cardiac performance depressed by sodium pentobarbital in a dose-dependent manner. At $100 \mu \mathrm{g}$ of NKH477, cardiac function was almost restored to the control state, although this restoration was accompanied by tachycardia.

We also investigated the combination effects of NKH477 and ouabain on the cardiac failure induced by sodium pentobarbital. NKH477 further improved the cardiac function which had been partially restored by ouabain without inducing any arrhythmias, indicating the different mechanisms of action of both agents. Almost complete restoration of the cardiac performance of the failing heart was attained with the combination of $30 \mu \mathrm{g}$ of NKH477 with $30 \mu \mathrm{g}$ of ouabain. At these doses, the increase in heart rate was only about $12 \%$ of the control value and was not statistically significant, and no arrhythmia was induced. Thus, the combination therapy of NKH477 and cardiac glycosides may be useful for the treatment of heart failure, since the cardiotonic effect of NKH477 was additive to that of oua- 
Table 2. Liffects of NKH477 on heart rate (HR), the maximum rate of rise in left ven-

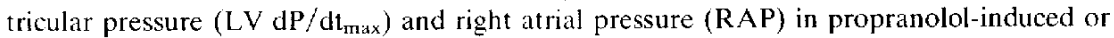
verapamil-induced heart failure

\begin{tabular}{|c|c|c|c|c|c|}
\hline & \multirow[t]{2}{*}{ Initial value } & \multirow[t]{2}{*}{ Heart failure } & \multicolumn{3}{|c|}{ NKH477 } \\
\hline & & & $10 \mu \mathrm{g}$ & $30 \mu \mathrm{g}$ & $100 \mu \mathrm{g}$ \\
\hline \multicolumn{6}{|c|}{ Propranolol-induced heart failure } \\
\hline $\begin{array}{c}\text { HR } \\
\text { (beats/min) }\end{array}$ & $137 \pm 5$ & $118+7$ & $129 \pm 8$ & $153 \pm 10$ & $201 \pm 9^{*}$ \\
\hline $\begin{array}{l}\mathrm{LV} \mathrm{dP} / \mathrm{dt}_{\max } \\
(\mathrm{mmHg} / \mathrm{sec})\end{array}$ & $1583 \pm 170$ & $883 \pm 111^{*}$ & $950 \pm 143$ & $1233 \pm 303$ & $2333 \pm 303^{*}$ \\
\hline $\begin{array}{c}\mathrm{RAP} \\
\left(\mathrm{cmH}_{2} \mathrm{O}\right)\end{array}$ & $1.7 \pm 0.3$ & $3.6 \pm 0.2^{*}$ & $3.5 \pm 0.2^{*}$ & $2.9+0.2^{*}$ & $1.8 \pm 0.2$ \\
\hline \multicolumn{6}{|c|}{ Verapanil-induced heart failure } \\
\hline $\begin{array}{c}\text { HR } \\
\text { (beats/min) }\end{array}$ & $149+6$ & $127 \pm 6$ & $133 \pm 8$ & $150 \pm 9$ & $188 \pm 8^{*}$ \\
\hline $\begin{array}{l}\mathrm{LV} \mathrm{dP} / \mathrm{dt}_{\max } \\
(\mathrm{mmHg} / \mathrm{sec})\end{array}$ & $1767 \pm 61$ & $1233 ! 42^{*}$ & $1233 \pm 42^{*}$ & $1500 \pm 68$ & $2433 \pm 214^{*}$ \\
\hline $\begin{array}{c}\mathrm{RAP} \\
\left(\mathrm{cmH}_{2} \mathrm{O}\right)\end{array}$ & $1.5 \pm 0.2$ & $4.0 \pm 0.4^{*}$ & $3.8 \pm 0.3^{*}$ & $3.0 \pm 0.3^{*}$ & $1.8+0.2$ \\
\hline
\end{tabular}

Values obtained just before the competence test at each dose of NKH477 are shown. Each value represents the mean + S.E.M. of 6 preparations. ${ }^{*} \mathrm{P}<0.05$ vs. initial value.

bain. NKH477 may ameliorate the elevation of peripheral resistance induced by cardiac glycosides by virtue of its direct vasodilator effect (6) and also the latter may modify the positive chronotropic effect of the former.

NKH477 also improved the cardiac function depressed by propranolol or verapamil as well as the case by pentobarbital. At a dose of 100 $\mu \mathrm{g}$, the cardiac function curves depressed by propranolol or verapamil were completely restored to the control statc. Therefore, NKH477 was equally effective in propranolol-, verapamil- or pentobarbital-induced heart failure, suggesting that the mechanism of the positive inotropic effect of NKH477 does not involve the $\beta$-adrenoceptor stimulation or the Ca-agonistic action. Thus, the effect of NKH477 is non-specific for several drug-induced heart failure models, and hence NKH477 may be useful for the treatment of various types of heart failure.

Recently, some of the novel cardiotonics were evaluated for their ability to improve pentobarbital-induced heart failure in the dog heart-lung preparation $(7-9)$. When com- pared in the doses that restored the depressed cardiac function curve to the control level, NKH477 appears to be as potent as denopamine (8) and MCI-154 (7) and more than 100 times more potent than amrinone (9). Amrinone failed to restore the depressed cardiac function curve to the control level at the dose of $10 \mathrm{mg}$, and no more restoration was observed even with $30 \mathrm{mg}$ of amrinone (9). In this respect, $\mathrm{NKH} 477$ appears superior to amrinone as a cardiotonic drug. However, although it is difficult to compare directly, NKH477 seems to be slightly more positively chronotropic than amrinone (9) and to be as positively chronotropic as denopamine (8), when compared at the doses which produce a similar restoration of the cardiac function.

In the present study, NKH477 was cumulatively administered into the blood reservoir, and the effects of NKH477 reached steady levels in 15 to $20 \mathrm{~min}$ after each administration. On the other hand, forskolin was reported to reach a steady level of contractile force within $10 \mathrm{~min}$ in isolated canine ventricular muscle (10). Thus, NKH477 appears to 
have slower developing effects than forskolin, although the pharmacological properties of the two agents are similar $(2,6)$. Furthermore, although NKH477 is water-soluble (about 2000 times more water-soluble than forskolin), about $10 \%$ non-ionized NKH477 may be present under physiological conditions ( $\mathrm{pH} 7.4$ ), since the pKa value of NKH477 is about 8.46. These findings, taken together, suggest that NKH477, like forskolin, can permeate a membrane bilayer to act on the intracellular side of the cell plasma membrane.

The present study demonstrated that several drug-induced experimental cardiac failures were completely improved by NKH477, although a slight increase in heart rate was associated with this improvement. The cardiotonic effect of NKH477 was additive to that of ouabain. Furthermore, NKH477 in the doses used produced no arrhythmias, although further experiments will be needed to clarify whether the potentially arrhythmogenic action of NKH477 is different from that of catecholamines. In addition, NKH477 has been shown to have a potent vasodilator action (6). These results suggest that $\mathrm{NKH} 477$ would be a potentially useful cardiotonic and vasodilator drug.

\section{Acknowledgments}

We are grateful to Professor N. Taira, Department of Pharmacology, Tohoku University School of Medicine, Sendai, Japan, for his advice and suggestions during preparation of the manuscript.

\section{REFERENCES}

1 Wetzel, B. and Hauel, N.: New cardiotonic agents - a promising approach for trcatment of heart failure. Trends Pharmacol. Sci. 9, 166-170 (1988)

2 Metzger, H. and Lindner, E.: "The positive inotropic-acting forskolin, a potent adenylate cyclase activator. Arzneimittelforschung 31, 1248 $1250(1981)$

3 Metzger, H. and Lindner, E.: Forskolin-a novel adenylate cyclase activator. IRCS Med. Sci. 9, 99 (1981)

4 Seamon, K.B., Padgett, W. and Daly, J.W.: Forskolin - unique diterpene activator of adenylate cyclase in membranes and in intact cells. Proc. Natl. Acad. Sci. 78, 3363-3367 (1981)

5 Tatec, T., Narita, A., Narita, K., Izumi, G., Takahira, T., Sakurai, M. et al.: Novel and potent water-soluble forskolins. Abstract of the 201st National Meeting of the American Chemical Society, Atlanta, April 14-19, MEDI 80 (1991)

6 Hosono, M., Takahira, T., Fujita, A., Fujihara, R., Ishizuka, O., Ohoi, I. et al.: Cardiovascular effects of NKH477. a novel potent water-soluble forskolin derivative. Eur. J. Pharmacol. 183, 2110P (1990)

7 Satoh, K., Nunoki, K., Goto, T., Hosono, M., Hashimoto, H., Sato, Y. et al.: Improvement of pentobarbital-induced heart failure by $\mathrm{MCI}-154$, a novel and potent cardiotonic agent, in the dog heart-lung preparation. Japan. J. Pharmacol. 47, $189-195$ (1988)

8 Nunoki, K., Goto, T., Satoh, K. and Taira, N.: Improvement by denopamine (TA-064) of pentobarbital-induced cardiac failure in the dog heart-lung preparation. Heart Vessels 1, 216-219 (1985)

9 Satoh, K., Maruyama, M. and Taira, N.: The improvement of cardiac performance by amrinone, a new cardiotonic drug, in an experimental failing heart preparation of the dog. Japan. Heart J. 23, 975-980 (1982)

10 Endoh, M., Yanagisawa, T., Taira, N. and Blinks, J.R.: Effects of new inotropic agents on cyclic nucleotide metabolism and calcium transients in canine ventricular muscle. Circulation 73, Supp. III, $117-133(1986)$ 